\title{
Konflikt, kogemus ja nostalgia perepärimuses Eesti ja Soome näitel
}

\author{
Tiiu Jaago
}

Jutte esivanematest, perekonnanime päritolust, pereliikmete omadustest ja tegevusest leiame tänapäeval nii suulisest traditsioonist, kui kirjalikest suguvõsakroonikatest, mälestustest, autobiograafiatest, kuid ka ajakirjandusest (näiteks intervjuudest). Mõnikord panevad esivanemaid meenutama üsna ootamatud assotsiatsioonid.

\section{Kas sul maal või metsas ka keegi elab? \\ Mu vanaema elab Suure-Jaanis Jaama tänava kollases majas. Ma ise olen ka Suure- Jaani kirikus ristitud ja leeris käinud. Aga ma olin siis neliteist ja ega ma sellest suurt midagi ei mäleta. \\ Seda mäletad, missugune kleit sul seljas oli? \\ Mul oli valge seelik ja valge pluus. Ja ma olin paks laps. Muuseas, vanaisa vanaisa on Rootsist kelguga üle jää Eestisse tulnud. Ta oli vist mingi kingsepp olnud või selline asi. (Jürgen 1998: 12).}

Esivanemate päritolu tundmisel on olnud nii müütilisi, juriidilisi kui ka teaduslikke funktsioone (Mitterauer 1991; Merila-Hubbard 1995). Kuid miks kõneldakse ja kirjutatakse sellest tänapäeva ühiskonnas? Vahetut praktilist tähtsust sellel ei ole: ainult pärimusele tuginedes ei ole võimalik lahendada ühtki juriidilist probleemi olgu see siis pärimisõigus või kodakondsuse saavutamine; siinkandis pole levinud usundeid, mis seovad oma rühma liikmeid ühise esivanema ja veresuguluse kaudu. Teaduslikud uurimused (genealoogia, veresugulusest tingitud geneetilised seosed) tuginevad esmajärjekorras dokumentaalselt tõestatud materjalile, mida aga pärimus iseenesest kunagi olla ei saa.

Võib oletada, et muutused ühiskonnas elavdavad päritolutundmist. Näiteks elavnes genealoogia tundmise vajadus 1990. aastatel seoses Eesti kodakondsuse taotlemisega, samuti seoses õigusvastaselt võõrandatud vara tagasitaotlemise või selle kompenseerimise taotlemisega. Viimastel aastatel eeldatakse koolilastelt suguvõsa tundmist (näiteks käsitletakse Tiia Toometi kirjutatud V klassi ajalooõpikus peatükis «Me elame ajaloos» suguvõsa ja selle tundmist); uurimistöö tarvis on läbi viidud spetsiaalseid küsitlusi (näiteks Tiit Tuumalu bakalaureusetöö «Perekonnanimi rahvaluule ainena» 1997. aastal). Ometi on need üksikseigad, millel ei ole pikaaegset ja ühtlasi traditsiooni kujundavat võimet. Perepärimuse viljelemise põhjusi tuleb otsida varasema traditsiooni ja uute kultuurinähtuste ühtsusest, mistõttu suulise pärimuse jäik eraldamine pärimuse kirjalikest vormidest pole võimalik.

\section{Vajalikke eelmärkusi}

Perepärimusel on kaks tahku. Esimene neist on pärimuses jutustatav, selles leiduva informatsiooni eripära (mida räägitakse või mida kirjutatakse). Teine on aga vorm, see, kuidas jutustatakse ja kirjutatakse, kuidas lugu esitatakse. Perepärimusel on olemas vastav traditsiooniline väljendusvorm.

Pärimuslik ajalugu ja isikulugu on vaid üks vaatenurk sellele, mis tegelikult juhtus. Jututõel on oma seesmine loogika, mis ei tähenda faktide objektiivset meenutamist. Jutuomane minevikunägemus sõltub ajastu maitsest, arvamustest ja hoiakutest, need mõjutavad jutus- 
tamist ja muutuvad jutustamishetke vajadustest lähtuvalt. 20. sajandi alguse eesti päritolujuttudele on tüüpiline, et väidetakse, nagu oleksid esivanemad tulnud Rootsist. Martin Lipp peab selle põhjuseks talupoja-pärisorja taustaga linnainimeste alaväärsuskompleksi (Lipp 1909). Samast ajast pärit talupojapärimuses ei näi see põhjus domineerivat, kuigi rootsi päritolu esivanemad on sagedased nendegi juttudes. Pigem on siin mujalt tulnud esiisa motiiv allutatud Rootsist tulnud esiisa motiivile (Jaago \& Jaago 1996).

Aeg-ruum kujundab pärimusteavet, muudab selle eripäraseks, sealjuures ka kõrvalekaldumised ajaloofaktidest. Aeg-ruumist on tingitud ka traditsioonilise väljendusvormi olemasolu ja eripära. Mitte kõik ja kõikjal ei räägi kõigest. Nii võiks piltlikult kujutleda, et igas geograafilises punktis on pärimusel oma traditsiooni telgjoon, mis ühendab minevikku olevikuga. Neid geograafilisi telgjooni läbivad ühed ja samad ajaloosündmused (sõjad, poliitilised ja usuliikumised, perekonnanimede panek) ning kultuuritasandid (kirjaoskus, koolisüsteem), mis küll mõjutavad neid geograafilisi pärimustelgi, kuid tulemus kujuneb ikka vertikaalsete ja horisontaalsete telgede koosmõjus. Seetõttu juhin siin eriti tähelepanu sellele, et me saame käsitleda perepärimust vaid seal, kus on olemas vastav jututraditsioon, sh sobivad pärimusvormid. Seega soome või eesti perepärimus ei kata kogu Soome või Eesti ala ühtlaselt pärimusmaastik ei kattu looduses nähtava maastikuga.

\section{Põhiprobleem ja allikad}

Küsimuse, miks kõneldakse esivanematest ja pere liikmetest tänapäeval, seadis minu jaoks uurimiskeskmesse jutuajamine Åbo Akadeemia folklorist Ulrika Wolf-Knutsiga. Ta oli uurinud pagulaste pärimust ja leidis, et suguvõsa ning pere minevikust jutustamine on seotud oluliselt nostalgiaga. See oli minu jaoks üllatus: ma ei saanud tema väidet küll tagasi lükata, kuid Eesti alal kogutud ja kogetud materjali põhjal nostalgia esiplaanil ei olnud. $\mathbf{1}$ Siit tulenes minu eesmärk - uurida seda, mis kannab pere isikuloolisi ja ajaloolisi pärimuslugusid praegu. Aluseks võtsin varasemale materjalile lisaks aastatel 1996-1997 Eestis ja Soomes kogutud perepärimust sisaldavad kirjapanekud.

1. Tartu Kirjandusmuuseumi Eesti Kultuuriloolises Arhiivis asub ühenduse «Eesti Elulood» materjal, mis on saadud kogumisvõistluse tulemusena, teemaks «Minu ja minu lähedaste saatus ajaloo keerdkäikudes». Laekus umbes 20000 lk, millest töötasin läbi ligikaudu $1500 \mathrm{lk}$.

2. Helsingi Soome Kirjanduse Seltsi rahvaluule arhiivi kogu «Suvun suuri kertomus» (Suguvõsa suur jutustus), mis on 1997. aasta soome perepärimuse kogumisvõistluse tulemus. Töötasin läbi umbes 1300 lk 40 000-st.

Eesti materjali puhul lähtusin peamiselt nende pärimussisaldusest (kogu on elulookeskne, mistõttu esivanemate päritolu ja elu peegeldavaid jutte ei pruugi me sealt leida). Soome materjali puhul eelistasin talupojapäritolu lugusid, kuivõrd see haakus mulle seni tuntud eesti materjaliga kõige enam.

Kuigi ma ei jälginud sihipäraselt kirjutaja sugu, sünniaastat ega päritolugeograafiat, tulevad need andmed esile. Nii eesti kui ka soome allikakogus on naiste töid kaks korda rohkem kui meeste omi - seega aktiivsemad kirjutajad on naised. Naiste ja meeste tööd erinevad sedavõrd, et äärmuslikke tendentse jälgides näeme, milline esituslaad on tüüpilisem meestele, milline naistele. Kõige enam kirjutavad 60-70-aastased. Just nende kirjutajate ajataust (II 
maailmasõja eel valitses ühiskonnas stabiilsus, mis on kontrastne maailmasõjaaegsete ja -järgsete murrangute ajastuga) kujundab pärimuse sisu ning rõhuasetused. Kõigi kirjutajate geograafilist tausta ma ei uurinud, kuid läbitöötatud materjali põhjal eristuvad Eestis vertikaalselt keskteljelt ida ja lääne poole jäävad alad. Idapoolne ala on «jutukam», jutulikum ja inimesse sissevaatlikum. Läänepoolne ala on teabekesksem, jutud on napimad. Omaette regiooni moodustab Saaremaa.

Loetud 14 tööst on üks Saaremaalt; kolm Lääne-Eestist (kusjuures üks autoritest on pärit Läänemaalt, ent suurema osa elust veetnud mujal, viimati Tartus); 9 pärineb idapoolselt alalt, ühe kohta puuduvad andmed.

Soome tööd olid suures osas pärit Karjalast, Kesk-, Põhja- ja Ida-Soomest. Julgen arvata, et ka seal on põhjuseks jututraditsiooni tugevam põhi. Näiteks üks töö, saadetud LääneSoomest (Uudenkaupunki), sisaldab ennekõike ja suures osas isapoolse suguvõsa pärimust Karjala ajast. Kõrvutuseks esitatakse vaid mõned leheküljed kohalikust ja ema suguvõsaga seonduvast pärimusest (SSK 9139/9787). Lappeenrannast pärit naine analüüsib oma lapsepõlve ja suhteid perega. Sealjuures märgib ta, et tema karjalasest mees jutustas oma perest palju ja vabalt pikki lugusid. Naine ise seda ei oska, neil peres nii ei olnud. Ta tunneb ennast kirjutades paremini (SSK 9505/10096, lk 11888). Traditsioonipinnas kujundab teadmiste, aga ka emotsioonide ja arusaamade väljendamise laadi ning vormi.

\section{Talu ja perepärimus}

Seni olin tegelnud taluperedest võrsunute suulise pärimusega (või selle kirjapanekutega), mis kõneleb ajavahemikust «pärast Põhjasõda» (see on rahvapärane ajamääratlus) kuni II maailmasõjani. Seda materjali iseloomustab:

1. kodu- (talu-) ja esivanemate teema põimumine; kui kõneldakse ühest, kõneldakse ka teisest;

2. pärimus «ehitatakse üles» sugupuu tundmisele.

Näiteks: 20. sajandi alguse Läänemaa talupidaja, andes talu üle oma pojale, annab ühtlasi edasi ka vajalikud teated esivanematest, sõnadega: Meie armsale pojale Aleksandrile, temale, kellele oleme päranduseks andnud Kohatu Jaani (Jaanimardi) nr 10. talu, anname siinjuures andmed, mis temale, ta lastele ja lastelastele mälestuseks jäävad veel siis, kui meist rohkem järele ei ole jäänud, kui lilledega ehitatud või rohtu kasvanud hauaküngas. Järgnevad andmed suguvõsa kohta (EE 570, lk 1). Jutustades oma lapsepõlvekodust, esitab 60-ndates eluaastates Harjumaa naine ka oma talu loo viie põlve vältel: esiisa Toomas oli ihne rahakorjaja, kes rentis oma pojale Jürile Harjumaa ja Läänemaa piirile Heldemaa kõrtsi, kes omakorda kogus hea kõrtsmikuna raha oma pojale Hansule, nii et too saigi osta talu 50-aastase võla peale, talu pidas Hansu järglasena poeg Jaan, viimase võla maksis talu eest Jaani tütar Hilja (snd 1911) 1936. aastal (ERM, KV 745, lk 170). Meeleolukas analoogiline pärimus kõneleb, kuidas vanemale pojale talupärijale - pandi nimeks vaheldumisi Hindrek ja siis Jaan; mis Hindrekute ajal ehitati, see Jaanide ajal lagunes (ERM, KV 752, lk

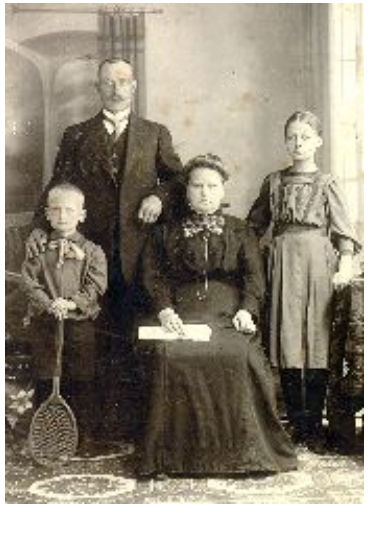
287). 
Pärimusmotiivid jäävad aja muutudes küll püsima, kuid muutub nende juttude kontekst. Ka praegu tuntakse sugupuud ja see võib aluseks olla juttudele esivanematest, kuid see ei seostu enam talu loomisega, sest talu on reeglina reaalselt olematu.

Taluelu kajastub ka neis kahes eelnimetatud kogus «Minu ja minu lähedaste saatus ajaloo keerdkäikudes», mis asub Tartus, ja «Suvun suuri kertomus», asukohaga Helsingis. 60-70aastaste põlvkond kirjutab oma vanemate elust 20. sajandi alguses. Selle järgi ei olnud vanemate noorpõlv kerge, seda peamiselt vaesuse ja raske töö tõttu. Näiteks 62-aastane soome naine Impilahtist kirjutab: vanemad olid küll jutukad, kuid oma lapsepõlvest nad ei rääkinud see oli raske ja raskustest ei tahetud kõnelda (SSK 9509/10102, lk 6429). 70-aastane eesti mees Lääne-Virumaalt mainib, et vanemate noorpõlveaeg oli rentnikuaeg ja see oli raske. Seevastu tema enda lapsepõlv oli rahulik ja õnnelik, puudust ei tuntud millestki (EE 540, 1k 69).

Tänapäeva pärimusekirjutajate mälestustes ongi üheks taluelu kirjeldamise erijooneks see, et vastandatakse taluelu stabiilsus ja harmoonia pärast II maailmasõda toimunud murrangule. Sellel on objektiivne alus nii kõnesoleva põlvkonna elukaare tõttu kui ka ajaloosündmuste tõttu. Need kirjutajad olid lapsed 1920- ja 1930 ndatel aastatel. Reeglina on lapsepõlv ilus aeg ja ei koorma inimest elumuredega. $\underline{2}$ Suhteliselt stabiilsele ja harmoonilisele lapsepõlvele järgneb väga järsuna tajutud murrang ühiskonnas. Eestis paiskavad tavaelu segamini sõda ja poliitilised ümberkorraldused, mille äärmuseks on vangistused ja küüditamised 1941. ja 1949. aastal. Soomes teeb seda sõda, Vene piiri nihutamisest tingitud väljaränne Karjalast, kuid olulisim muutus seostatakse kultuurimurranguga, kus senine loodusrütm vastandatakse tehnokraatiale.

Pärimuse kirjutajate elukogemustest ilmneb murrangutaju: ühelt poolt lapsepõlve stabiilsus ja harmoonia, mis seostub taluelu, pere ja sealtkaudu suguvõsa järjepidevusega; $\stackrel{3}{-}$ teiselt poolt tajutakse selle lõhkumist ühe või teise jõu poolt (poliitika, tehnikaajastu).

Ajastu murdejoonel asumine on soodustanud kontrasti - enne : pärast (või nüüd) - esitamist. See võiks tuua jutustustesse nostalgia, kuid vaadeldud allikmaterjalis see ei ole domineeriv. Üks selgepiiriline kontrasti esitamise viis on hoopis konfliktile ülesehitatud jutustus. Minu poolt uuritud pärimusmaterjalis on «nostalgia» asemel keskne «konflikt».

\section{Konfliktjutustus}

Konflikt on telgjoon, millele saab üles ehitada jutustust. Kuid oluline on ka see, et traditsioonis on konfliktjutustused juba varem olemas. Talupojapärimuses seostuvad need peamiselt naisevõtuteemaga, mehe ja naise või minia ja ämma suhetega (vt lähemalt Jaago \& Jaago 1996: 89-94).

Vaatleme esmalt näidet, kus kirjutaja on vastamisi välismaailma sündmustega ja püüab kirjutamise käigus välja elada tekkinud pinget. Konfliktjutustuste üks funktsioone on suhete korrastamine, nende selgitamine iseenda jaoks. 68-aastane naine Iisakust kirjeldab oma pere lugu kahel tasandil: ühe terviku moodustab lapsepõlv ja taluaeg, millega seonduvalt esitatakse ka esivanemate lugu; teise terviku moodustab talu hävingu lugu, millega seoses räägitakse ennetest (kuusk läheb 1940/1941. aasta jõuluajal ümber, koerad uluvad isa-ema akna taga); järgneb detailne ja kogu eluloojutustusest suuremat osa hõlmav Siberi-aja ning selle järelkajade kirjeldus. Naine ei kirjuta, mis juhtus pärast 1958. aastat, kui pere naasis Siberist Eestisse, vaid kirjeldab sellel perioodil esitatud rehabiliteerimistaotlusi ja ametnike vastuseid neile. Siit tulenev konflikt osutus kirjutatud eluloo «võtmeks». 
Miks rehabiliteerimine ei lahenda konflikti, mille vastandpoolusteks on koduelu ja Siberiaastad? Rehabiliteerimistaotluste vastused tekitavad uusi pingeid. Näiteks osutub, et vanaema, kes suri Siberis, ei ole saadud vastuse järgi küüditatute nimekirjas, ja tema kohta on öeldud, et see inimene ei olnudki Siberis! Aga miks ta siis suri Siberis (EE 402)?

Muidugi ei ole kõik Siberi-jutustused üles ehitatud konfliktile. Ainestik iseenesest ei tingi ega määra jutustamisvormi.

Välismaailma murrangulised sündmused võivad peegelduda inimese eneseanalüüsis. Ka järgneva näite autor püüab kirjutamise kaudu lahendada konflikti, kuid esialgu jõuab ta vaid probleemi tuumani. 45-aastane Rovaniemi mees analüüsib pere osatähtsust inimese kujunemisel ja mehe identiteedi muutumist kolme põlvkonna vältel. Ta kirjeldab mehe suhet loodusesse, oma peresse, haridusse, töösse ja hingelisusse erinevatel ajajärkudel vanaisaaegsest maailmast tänapäevani. Suhete kõrvutusest nähtub, et sõjaaja ja tehnikaajastu mees on kaotanud tasakaalu seoses eemaldumisega loodusest, perest ja hingelisusest. Kirjutaja jõuab järeldusele, et ta on elanud skeemi järgi, mis on talle ette pandud, kuid mis ei ole olemuslikult talle sobiv. Ta arvab, et sellise valulise enesetunde juured peituvad tema meheks kasvamise ajataustas: eelkõige ümberhinnangud suhtumises loodusesse ja inimesse selle osana; uued kultuurivõimalused, eelkõige haridus, mis ei mänginud külaühiskonna inertsi tõttu veel olulist osa (SSK 8239/9165). Kirjutis on analüüsiv, kurva alatooniga. See kulmineerub lõpus, kus hetkeolukorda võrreldakse lahtise haavaga Haava on auki iholla, veretön haava (samas, 1k 27469).

Konfliktile teljel mina ja välismaailma sündmused ehitavad oma kirjaliku jutustuse üles silmahakkavalt soome mehed, ${ }^{4}$ aga mitte naised. Seevastu üsna tavaline on see võte eesti naiste kirjutistes. Soome naisjutustajatele on iseloomulik konflikt mina ja pere või pere ja üksikisik, soome meeste jutustustele ei ole see iseloomulik. Eesti materjalis kirjutaja ja tema pere liikmete vahelised konfliktid küll kajastuvad, ent sellele vastuseadele jutustust üles ei ehitata. Seda ilmselt allika eripära tõttu (tegemist on isikukeskse, mitte perekeskse materjaliga), aga võimalik, et ka teistel põhjustel: nõukogude perioodil ei peetud perekonna osa isiksuse arengus tähtsaks, järelikult puudub sellise taustaga inimestel oskus analüüsida oma saatust perest lähtuvalt.

Vastandus (mina - ühiskond) esitatakse konfliktjutustustes samal aja- ja ajastuteljel (minevik - olevik). Konfliktjutustuses langeb sümpaatia selgelt ühele või teisele poole. Juhul kui materjalis ongi nostalgilisi minevikuvaateid, siis ei kuulu need lähiminevikku ega domineeri jutustuses tervikuna. Mineviku ja tänapäeva vastandust ei pruugita esitada konfliktselt. Jutustaja ei keskendu nii selgelt ühele teljele (konfliktile), vaid võib kõnelda sündmustest laiaulatuslikumalt, millest koorub lõppkokkuvõttes välja üldistatud kogemus. Kogemusjutud võivad sisaldada alaosadena konfliktjutustusi. Näiteks Uusikaupungist pärit 40-ndates aastates mees ühendab tervikuks enda, Lääne-Soomest pärit ema ja Karjalast pärit isa mälestused. Lugu koosneb konfliktjutustusest (Karjala kodust lahkumine), etnoloogilisest kaluriküla olustiku ja kalapüügi kirjeldustest (kadunud kultuuri omalaadne säilitamisviis) ning lõpeb hinnangulise kokkuvõttega (sõda võttis kodu, kuid andis kogemuse; kuidas kodu on teda mõjutanud; mida see on tema jaoks tähendanud). (SSK 9139/9787, lk 371).

\section{Kogemusjutustus}

Vanematest ja vanavanematest jutustamisel, nende argielu meenutamisel märgitakse nende töö raskust. See on jutustajates äratanud lugupidamist ja aukartust, kuid ajendanud ka arutlema mineviku ja tänapäeva erinevuste üle. 40-aastane soome naine Kuopio lähedalt jõuab järeldu- 
sele, et tema vanemad tegid seda tööd, mis oli vaja teha. Ta jõuab järelduseni, et tänapäevane tööpuudus tuleneb suures osas just sellest, et valitakse tööd ja ei taheta teha enam seda tööd, mis on vaja teha (SSK 9040/2033, lk 3458). Juttude kaudu selgitati lastele vanemate (abielu)suhete keerukust, mida lapsed tookord ei osanud mõista, kuid mida nad oma elukogemuse najal tundma on õppinud (SSK 9269/2137, lk 513-527). 77-aastane naine Jämsäst arutleb kerjustest minevikus ja tänapäeval: varem kerjati külast külla ja talust tallu liikudes, küsiti süüa. Praegu peab ta analoogseks nähteks raadio, televisiooni ja ajakirjanduse kaudu levitatavat üleskutset annetada kellegi või millegi heaks (SSK 9136/979, lk 4515). 1924. a sündinud naine Joensuust märgib, et perepärimuslugu kirjutades mõistab ta, kui muutunud on maailm. Tema oli veel looduslaps - osa loodusest. Seda enam ei ole. Ta igatseb küll seda aega tagasi, kuid samas teab, et praegusel tehnikaajastul on vanal inimesel palju kergem elada. Nostalgian ja todellisuuden välillä on ristiriita! (Nostalgia ja tegelikkus on üksteisele vastukäivad). (SSK 9211/9832, lk 10334).

Reeglina sisaldavad need jutud suuremal või vähemal määral oma elukogemuse kõrvutamist teiste elukogemustega - mitte konflikti, vaid analoogiat; pere ja vanemate tähtsuse sõnastamist; oma olemasolu mõtestamist pereloo kaudu.

Kogemusjutud tulenevad inimese seesmisest äratundmisest. Välised sündmused võivad põhimõtteliselt olla samad: Siberisse saatmine ja vangistus inimese enda seisukohalt absurdsetel põhjustel, sõda, lähedaste kaotus, kuid jutustust ei ehitata üles konfliktile, vaid elukaarele (Eestis ühe inimese eluloole, Soomes pereloole).

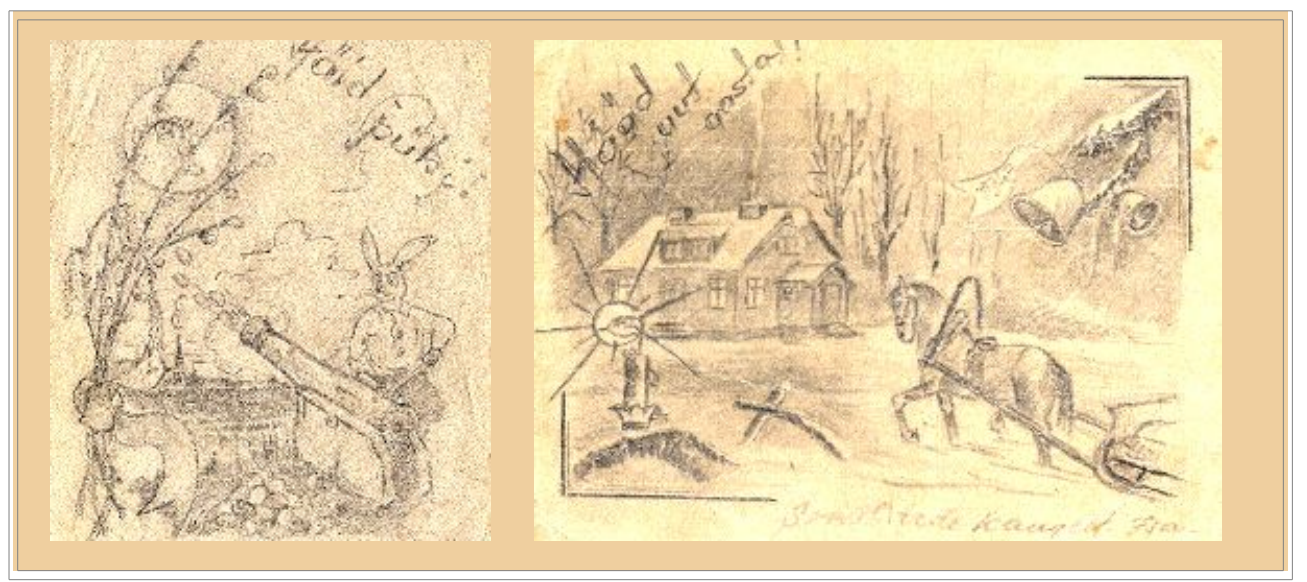

\section{Miks siis nii vähe nostalgiat?}

Nostalgia võib eelkirjeldatud pärimuses olemas olla taotluslikult, kuid jääda tagaplaanile. Võib leida taotlust meenutada kadunud kodu ilusat poolt, eesmärgiga tuua selle kaudu elevust tänapäeva ellu, mis ühtlasi oleks seotud ka identiteediga (mitte lihtsalt uus roog lauale, vaid mingi esivanemate Karjala roog). Minevikuihalus taandub möödanikku kuuluvate asjade või nähtuste olevikumõtestatuse ees.

Jutustamisel on jutustaja aktiivne. Kui ta kaldub nostalgiasse, siis jutustatav on suunatud jutustajale endale ja on üsna tõenäoline, et ta ei leia kuulajat - tekst ei ole suunatud kuulajale. Varjatult kandub perepärimus edasi etteheidete kaudu: Mina omal ajalàkas tegin mingit tööd, leppisin nii- või naasuguse toiduga, selliste esemetega (suuskade asemel paar lauda ja aiateibast võtsin kepid - käis küll). Need etteheited on tavaliselt suunatud lastele või laste- 
lastele. Ühelt poolt vahendatakse selliselt küll minevikku, kuid oma agressiivsusega peletatakse kuulaja eemale. See on niisamuti nagu nostalgia ütleja poolelt, enesekeskne väljenduslaad, mis on reeglina enesekaitse.

Igas kultuuris on olemas tunnustatud spetsiifilised väljendusvormid. Vaadeldud kultuuripiirkonna traditsioonis on olemas

1. konfliktist tulenevad jutustused kui pinge väljaelamise vorm. Selliste lugude teket soodustasid 20. sajandi keskpaiga pöördelised sündmused ja kultuurimurranguga seotud kohanemisraskused;

2. jutud kultuurimurrangule eelnenud taluelust kui stabiilsest ja harmoonilisest lapsepõlvemaailmast;

3. jutud esivanematest ja päritolust on mõjustatud eesti genealoogia aktiivsest viljelemisest, mis sai alguse 20. sajandi hakul baltisaksa genealoogia eeskujul;

4. kogemusjutud, millega vahendatakse teadmisi ja elukogemusi. Selline vahendamisviis, kus mitte ainult kirjanduse või meedia kaudu antakse kogemusi edasi (see on see elu, mitte ajalugu) on võõrvõimu all oleva rahva juures vältimatu;

5. identiteedi väljendamine päritolujuttude kaudu. Nii Eestis kui ka Soomes on esiplaanil kohapäritolu (esivanemad on tulnudà). Mõlema kultuuri jaoks on kust oled sa tulnud -teadmine enesetunnetuse määrav alus, määravam kui kes sa oled, sest see tuleneb eelmisest küsimusest. Teine oluline tugipunkt eesti pärimuses on nimi (pere- või perekonnanime päritolu), soome materjal seda ei kajasta.

Kõiki minu poolt läbitöötatud töid kannab armastus ja tänu vanemate vastu. Selliste lugude teadmine ja ülestähendamine on üks tänu ja armastuse väljendamise vorme.

Olemasolev traditsioonipinnas kujundab pärimuse suulise ja kirjaliku kujutamislaadi. Konfliktjutustus ei tulene mitte üksnes sellest, et ühel inimesel on ohuolukordi enam kui teisel, vaid ka sellest, et see on kirjutamise ja kõnelemise telg kultuuriruumis, kus stabiilsest olukorrast pole võimalik rääkida. Näiteks on Läänemaa naine jutustanud 1940. aastate talumaade osalisest äravõtmisest, küüditamise ja kolhooside loomise ebanormaalsusest. Muuhulgas tulevad esile jutustajapoolsed rõhuasetused, asjaolud, mis olid probleemiks konkreetselt talle:

1940. aasta pööret tean niipalju, et 30 ha maad jäeti. Kel rohkem oli, see võeti ära, küsiti ka, kust tahad ära anda, aga tehti risti vastupidi. Meilt läks ülejõe heinamaa [- -] nii et hobuste heina ei jäänud. Hobused paluheina ei söönud, sõimed seisid täis ja hobused jäid kõhnaks. Sel heinal oli münti sees, seda hobused ei tahtnud [ ] (EE 570, 1k 7).

Olukorra stabiliseerumine ei välista konflikte:

[Kolhoosi ajal] Ka kartuleid ei tohtinud omal võtta, tuli kolhoositööl olla. Ma võtsin Otsal kinnist vagu, nägin, tuleb jälle mingi ametmees, jooksin jõe äärde lepikusse, olgugi et mul oli lehmalüpsi vaheaeg. Nii mitu korda. Pärast läks rahulikumaks. Üks kevad Mardi Karla ajas meile kartulivagusid sisse, vana Veerpalu tuli, üks teine oli $k a$, saime mõlemad riielda. Aga nüüd ei ole mul vist enam midagi kirjutada (EE 570, 1k 11).

Nii järsku ja just nii ta lõpetabki. 
Tänu kultuuris olemasolevatele stereotüüpidele on perepärimus rahvaluule uurijale huvitav - pärimus ei vahenda mitte üksnes ajaloofakte, vaid vahendab ka inimeste hoiakuid, senist traditsiooni, kultuuri erijooni, erinevaid jutuskeeme - millest ja kuidas saab jutustada.

\section{Allikad}

EE - Kirjandusmuuseumi Eesti Kultuuuriloolises Arhiivis asuv kogu «Eesti elulood». Tartu. ERM, KV - Eesti Rahva Muuseum, korrespondentide vastused. Küsitlus «Kodu ja pere». Tartu.

SSK = SKS.SUKU - Suomen Kirjallisuuden Seura, kogu «Suvun suuri kertomus». Helsinki.

\section{Kirjandus}

Jaago, Tiiu \& Jaago, Kalev 1996. See olevat olnudà Rahvaluulekeskne uurimus esivanemate lugudest. Tartu.

Jürgen, Madis 1998. Evelin kõnnib öösiti. /Intervjuu Evelin Samueliga./ Favoriit. Mai 1998, $1 \mathrm{k} 8-14$.

Merila-Hubbard, Siiri 1995. Walesi ajaloost ja kirjandusest. Akadeemia, nr 10, lk 2115-2140. Mitterauer, Michael 1991. Funktionsverlust der Familie? Mitterauer, Michael \& Sieder, Reinhard (Ed.). Vom Patriarchat zur Partnerschaft. München, lk 100-125.

Lipp, Martin 1909. Eesti suguvõsade uurimine. Eesti Kirjandus, lk 3-15; 66-73.

\section{Kommentaarid}

1. Kõige selgemini nähtub müütilisusega põimunud nostalgilisus 1930. aastate suguvõsakroonikates, kus väljendatakse rõõmu kodutalu pärandamisest isalt pojale läbi mitme põlve. Neis käsitlustes tuuakse minevikust esile vaid positiivseks peetavaid asjaolusid.

2. Vt näiteks eluloojutustuse dünaamikat: lapsepõlvekirjeldusi läbib looduse ja töö vaheldumisest tingitud rütm. Endast väljaspool olevaid sündmusi ei seata esiplaanile. See peegeldub ka alapealkirjades nagu «Külm talv», «Töörohke kevad». Isa haigestumine ja surm lisab sellesse rütmi probleeme, nii pealkirjadesse («Murelik sügis») kui ka kirjeldustesse (Peale papa matuseid vahib mulle näkku elu raske argipäev. Ei ta küsi, kui vana või kui tugev sa oled, vaid nõuab sult kohe tegusid). On juba sõjaaeg, kuid sõda veel ei puuduta teda, kuigi peagi jõuab kirjutaja ka nende valikute ette, mille on toonud sõda (EE 430). 
3. Eestis langes käesolevalt kirjeldatud lapsepõlveaeg tõepoolest kokku taluelu teatava tõusuajaga.

4. Vt võrdluseks näiteks: mees Kuopiost (SSK 8205/9137), kes teab oma esivanemaid 12 põlve tagasi, kirjeldab, et nad kõik on elanud looduse osana, 13. põlv aga enam mitte ( $1 \mathrm{k}$ 8856). Tema ise satub murranguaega: enne teda oldi taluinimesed, tema ise õppis õpetajaks. Isa oli üllatunud: kas selle töö eest makstakse ka? Hänen mielestään kunnon töitä olivat turpeen puskeminen ja kirveen ja pokasahan kanssa metsässä ryskäminen (Tema meelest olid tõelised tööd maa tuhnimine ja kirve ning saega metsas müristamine) ( $1 \mathrm{k} \mathrm{8857).} \mathrm{Ta} \mathrm{ise} \mathrm{ei} \mathrm{mõista} \mathrm{oma} \mathrm{lapsi} \mathrm{ja} \mathrm{lapselapsi} \mathrm{ning} \mathrm{tunneb}$ end kui võõral maal Paabeli jõe ääres, kus «teised maad» on järgmised põlvkonnad (lk 8857). Tema kirjutises on selge vastandus: enne ja nü̈̈d, kusjuures tema ise ei ole uue olukorraga kohanenud.

1924. aastal sündinud soome naine Joensuust (SSK 9211/9832) kirjutab taluelust ja isakodu-ihalusest. Talu on tema jaoks puhkusekoht. Ta kirjutab kultuurimurrangust, mis kulges loodusest tehnikamaailma, kuid ei kahetse kuskil seda muutust, ei igatse taga varasemaid aegu. Ta ei arva, et tänapäeva lastel oleks kergem või raskem kui neil omal ajal. Ta on usklik ja on kindel, et Jumal on kõigiga (lk 10372). Igaühel meist on OMA koht ja OMA tähendus - ei mingit konflikti maailmaga. Elämäni voima, ilo ja rauha on Jeesus Kristus. Opin tuntemaan hänet äidin kuoleman jälkeen v. 1974, ja tiedän, että hän on kulkenut kanssani päivästä päivään koko elämäni ajan (Minu elu jõud, rõõm ja rahu on Jeesus Kristus, õppisin teda tundma ema surma järel 1974. aastal ja tean, et ta on käinud minuga koos päevast päeva kogu mu eluaja) (lk 10360). 